\title{
Growth Performance of Primed Okra (Abelmoschus esculentus L.) Seeds in Arsenic Contaminated Soil
}

\author{
${ }^{1 *}$ Erhenhi, A.H., ${ }^{2}$ Lemy, E.E., ${ }^{3}$ vwioko, D.E. And ${ }^{1}$ Okuhon, O.J. \\ ${ }^{1}$ Department of Botany, Delta State University, Abraka, Nigeria \\ ${ }^{2}$ Department of Animal and Environmental Biology, University of Benin, Benin City, Nigeria \\ ${ }^{3}$ Department of Plant Biology and Biotechnology, University of Benin, Benin City, Nigeria
}

Correspondence Author: Erhenhi, A.H. ${ }^{1}$ Department of Botany, Delta State University, Abraka, Nigeria.

Email: erhenhiah@gmail.com; +2348067749296

Received date: 28 January 2019, Accepted date: 13 March 2019, Online date: 28 March 2019

Copyright: () 2019 Erhenhi, A.H et al., This is an open-access article distributed under the terms of the Creative Commons Attribution License, which permits unrestricted use, distribution, and reproduction in any medium, provided the original author and source are credited.

\begin{abstract}
This study was carried out to evaluate the growth performance of primed seeds of okra (Abelmoschus esculentus L.) in arsenic contaminated soil using salicylic acid. Clemson spineless variety of okra purchased from Primier seed company, Benin City, Nigeria were subject to arsenic pollution at $50 \mathrm{ppm}, 100 \mathrm{ppm}$ and $150 \mathrm{ppm}$ treatment. The results showed that seed treatment with salicylic acid enhance germination and growth compared to non-treated seeds. Treated seeds grown in lower concentration (50ppm) had better performance in terms of germination $(75 \%)$ compared to those grown in higher concentration $(150 \mathrm{ppm})$ which had $10 \%$ germination rate. Untreated seeds were observed to have highest percentage germination of $55 \%$ in the $50 \mathrm{ppm}$ arsenic polluted soil while $25 \%$ was recorded for the $150 \mathrm{ppm}$ arsenic polluted soil. Plant height, stem girth and leaf area of treated seeds also showed better compared to non-treated seeds. The study showed that application ant treatment of seeds with salicylic acid improved the germination and growth of okra seeds grown on arsenic acid polluted soil compared to untreated seeds. Hence, seed priming with different concentrations can be successfully used to improve the germination and seedling growth in okra seeds as well as other economic crops in contaminated soil..
\end{abstract}

Keywords: Priming, pollution study, contaminants, plant growth parameters.

\section{INTRODUCTION}

Environmental contaminations and pollutants are the by-products associated with industrial revolution and advancement in modern technology which is further aggravated by over population and subsequent mismanagement of resources. Metals are naturally available and forms essential components of the environment which are essential requirements for plants as micronutrients (Taiz and Zeiger, 2006). Among naturally occurring metal is arsenic (As) which is a ubiquitous and carcinogenic trace metalloid which are present in the environment exists in various organic and inorganic forms. Industrial activities including oil exploration, mining, dredging and high level of industrialization within the oil rich Niger Delta area of Nigeria has resulted in contamination of soil with arsenics and other metals. Also, naturally and through human activities such as the use of various arsenical pesticides, wood preservatives, industrial wastes and growth promoters for plants and animals, the environment has been flooded with this toxic metal (Mei et al., 2012). The level of plant tolerance varies between species of different genotypes.

Priming of seeds are important methods associated with the ability of seeds grown in certain environment to germinate as it quickens the germination process and of seeds development (Hussein, 2017). Seed priming results in the enhancement of seeds and uniformity in germination under adverse environmental condition as well as fostering the development of seeds in vast agroclimatic conditions and declines sensitivity to external factors (Ashraf and Foolad, 2005). The ability to germinate and grow well is usually enhanced by implementing growth hormones and regulators during treatment. This and many other factors call for the introduction of seed priming using antioxidants such as salicylic acid (SA) which have been implicated in the alleviationof plant stress in saline environment (Afzal ey al., 2005). SA, an endogenous growth regulator which is a representative of the phenolic acid result in ionic transport and uptake, membrane permeability, stomatal closure and photosynthesis in plants. It also fosters germination and growth rate (Hussein, 2017). 
Citation: Erhenhi, A.H, et al., Growth Performance of Primed Okra (Abelmoschus esculentus L.) Seeds in Arsenic Contaminated Soil. Australian Journal of Basic and Applied Sciences, 13(4): 45-49. DOI: 10.22587/ajbas.2019.13.4.7

Seed priming using salicylic acid also result in seed resistance to stress caused by osmotic pressure, temperature and can also regulate plant biochemical and physiological activities (Canakci, 2011). Based on the importance of seed priming and the importance of SA in plant growth and development, the present study was carried out with the aim of evaluating the growth performance of primed seeds of okra (Abelmoschus esculentus L.) in arsenic contaminated soil.

\section{Study Area}

\section{MATERIALS AND METHODS}

This study was carried out at the Faculty of Science, Delta State University, Abraka, Nigeria in 2018. Clemson spineless lady's finger variety of okra (Abelmoschus esculentus L.) used for the study were obtained from Primier Seed Company in Benin City, Nigeria. Analytical grade arsenic salt (arsenic trioxide $\mathrm{As}_{2} \mathrm{O}_{3}$ ) of 50 milligrams was weighed using a sensitive balance in a measuring cylinder and stirred thoroughly was used to obtain 50ppm, 100ppm and 150ppm solutions using deionized water. Fifty (50) milligrams of salicylic acid was dissolved in 1 liter of deionized water to prepare 50ppm salicylic acid treatment. Three hundred millilitres $(300 \mathrm{ml})$ of the solution was poured in a beaker and viable seeds of okra were soaked in the solution for 2 hours before planting for seed priming. The experiment was setup using polypots with topsoil obtained from farm sites with four replications for each treatment (50ppm, 100ppm and 150ppm arsenic trioxide $\mathrm{As}_{2} \mathrm{O}_{3}$ ) and control (0ppm) using deionized water. After planting, $200 \mathrm{ml}$ of treatments were applied immediately and thereafter, every fourth day throughout the study period. Radical and plumule length protrusion was recorded as germination and the percentage was determined by counting. Plant height, stem girth and number of leaves were determined using standard methods and the mean and standard deviations were calculated for the values recorded in the study. Both the mean and standard deviations where performed where appropriate using the statistical package Microsoft - Excel Version-2010. Analysis of variance was carried out to ascertain the effects of the treatments (Gholamali et al., 2007).

\section{RESULTS}

The results obtained from the determination of the effects of varying concentrations of arsenic acid on treated and untreated salicylic seeds of okra are presented below. Table 1 shows the effects of arsenic acid polluted soil on the germination of primed and unprimed seeds of okra. The study showed that as the concentration of the pollutant increased, the percentage germination decreased with the lowest values recorded for 150ppm. The results obtained from seeds without priming showed that there were also effects of the pollutant (arsenic acid) as the day's increases after planting. However, there was higher rate of germination in the higher concentration (150ppm) compared to primed seeds.

Table 1. Percentage germination (\%) of primed and unprimed okra seeds grown on different concentrations of arsenic acid

\begin{tabular}{|c|c|c|c|c|c|c|c|c|c|c|}
\hline \multirow{2}{*}{$\begin{array}{l}\text { Conc. } \\
\text { (ppm) }\end{array}$} & \multicolumn{5}{|c|}{ Primed Okra Seeds } & \multicolumn{5}{|c|}{ Unprimed Okra Seeds } \\
\hline & 3 DAP & 6DAP & 9 DAP & 12DAP & 14DAP & 3 DAP & 6DAP & 9 DAP & 12DAP & 14DAP \\
\hline $\begin{array}{l}0.0 \\
\text { ppm }\end{array}$ & $65 \pm 10$ & $95 \pm 10$ & $95 \pm 10$ & $95 \pm 10$ & $95 \pm 10$ & $60 \pm 10.4$ & $75 \pm 12.01$ & $75 \pm 12.01$ & $75 \pm 12.01$ & $75 \pm 12.01$ \\
\hline $\begin{array}{l}50 \\
\mathrm{ppm}\end{array}$ & $60 \pm 16.33$ & $75 \pm 25.17$ & $75 \pm 25.17$ & $75 \pm 25.17$ & $75 \pm 25.17$ & $45 \pm 11.23$ & $55 \pm 21.14$ & $55 \pm 21.14$ & $55 \pm 21.14$ & $55 \pm 21.14$ \\
\hline $\begin{array}{l}100 \\
\text { ppm }\end{array}$ & $35 \pm 30$ & $40 \pm 36.51$ & $40 \pm 36.51$ & $40 \pm 36.51$ & $40 \pm 36.51$ & $30 \pm 13.17$ & $30 \pm 13.17$ & $30 \pm 13.17$ & $30 \pm 13.17$ & $30 \pm 13.17$ \\
\hline $\begin{array}{l}150 \\
\mathrm{ppm}\end{array}$ & $10 \pm 11.55$ & $10 \pm 11.55$ & $10 \pm 11.55$ & $10 \pm 11.55$ & $10 \pm 11.55$ & $20 \pm 11.15$ & $25 \pm 18.63$ & $25 \pm 18.63$ & $25 \pm 18.63$ & $25 \pm 18.63$ \\
\hline
\end{tabular}

Results are presented in Mean \pm SD, DAP: Days After Planting

Seed priming using salicylic acid at various concentrations of arsenic acid pollutant has been showed from the study to promote the growth of okra plant in terms of the plant height. Although there was higher growth of the plants in the control soil of the primed seeds, the various treatments concentrations showed tolerable performance in the plant height compared to the unprimed seeds which was relatively lower in plant height as the concentration of arsenic acid increased to $150 \mathrm{ppm}$ from 2 weeks to 6 weeks after planting (Figure 1). Variations in the plant height were recorded across all treatment concentrations $(0.0 \mathrm{ppm}$, 50ppm, $100 \mathrm{ppm}$ and $150 \mathrm{ppm}$ ) in both the primed and unprimed seeds. The result showed that as the weeks increased the plant height in the arsenic acid treatment of primed seeds increased with significant differenced $(P>0.05)$ compared to the unprimed seeds which showed insignificant level of increase $(P>0.05)$ in the plant height. 


\section{Primed Seeds Unprimed Seeds}

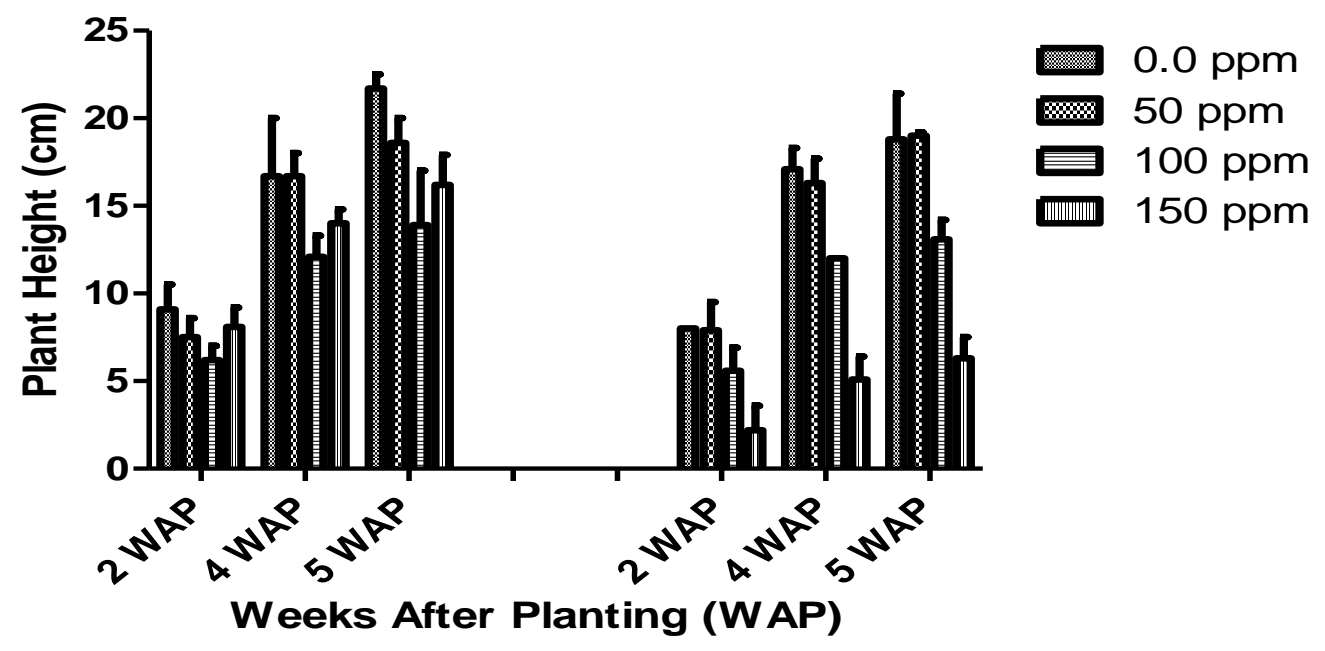

Figure 1. Plant height $(\mathrm{cm})$ of primed and unprimed okra seeds grown on different concentrations of arsenic acid

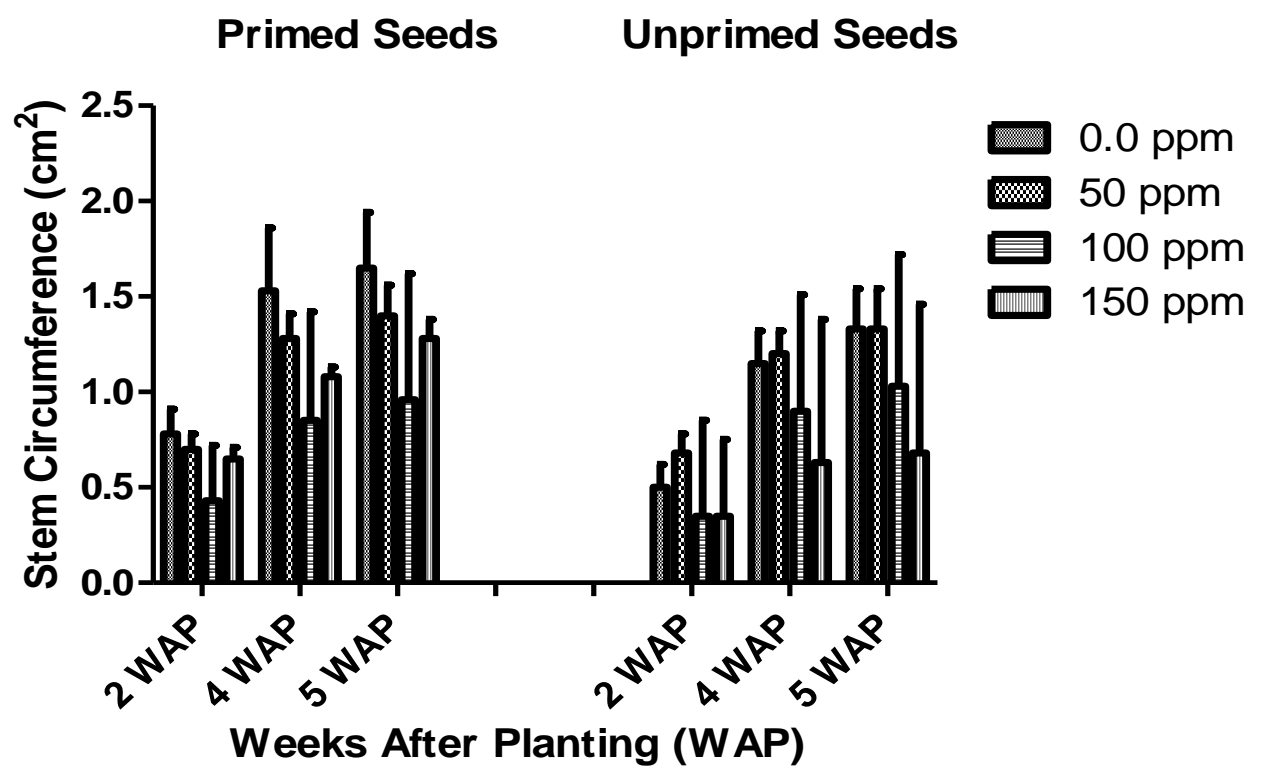

Figure 2 Stem circumferences $\left(\mathrm{cm}^{2}\right)$ of primed and unprimed okra seeds grown on different concentrations of arsenic acid

Production of leaves is an important parameter in the determination of plant growth both in treated and untreated soil. The results obtained from the present study showed that the treatment of soil with arsenic acid at higher concentration (100ppm and 150ppm) affected the production of leaves in the unprimed seeds when compared to the results obtained in primed okra seeds grown in arsenic contaminated soil (Figure 3). 


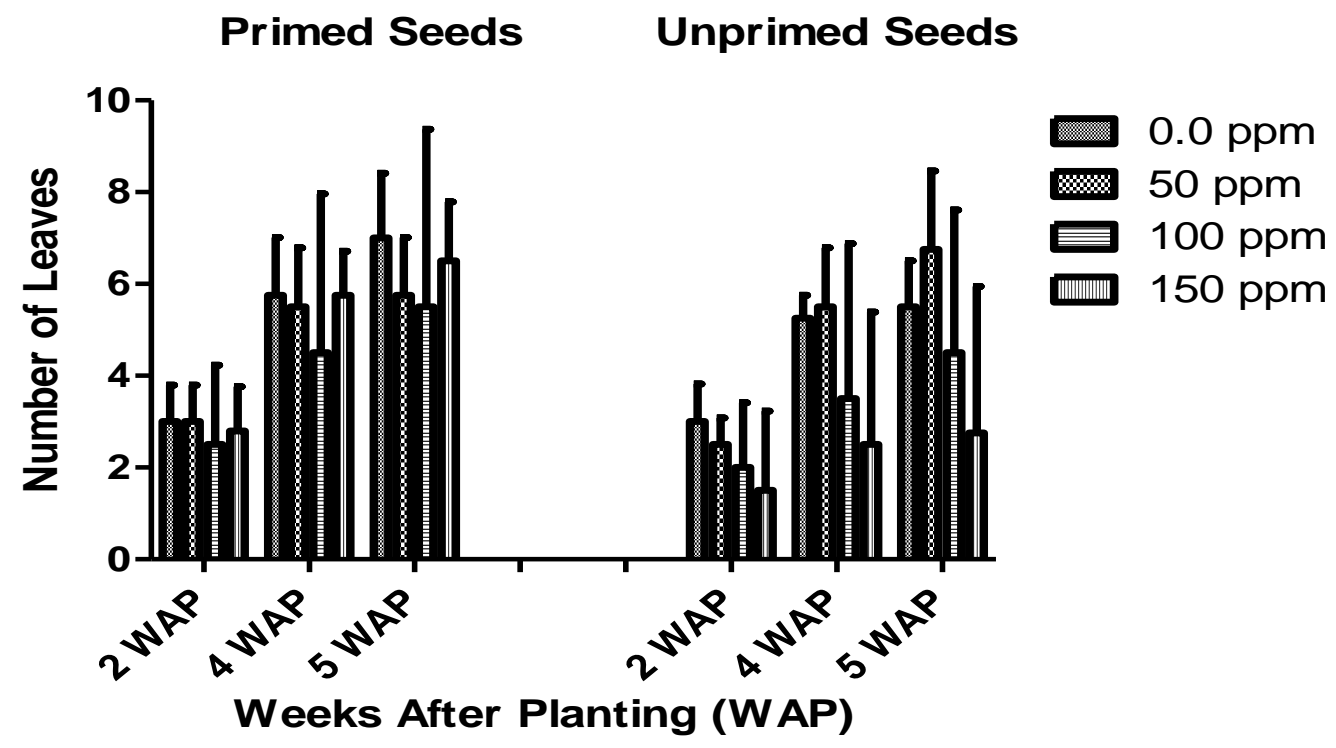

Figure 3. Number of leaves of primed and unprimed okra seeds grown on different concentrations of arsenic acid

\section{DISCUSSION}

The study evaluated the effects of seed priming on the growth of okra on arsenic acid polluted soil at various concentrations. The present study showed that there was higher plant performance in the treated seeds compared to the untreated seeds in terms of germination. Treated seeds grown in lower concentration $(50 \mathrm{ppm})$ had better performance in terms of germination $(75 \%)$ compared to higher to those grown in higher concentration $(150 \mathrm{ppm})$ which had $110 \%$ germination rate. This is in line with the report of Carvalho et al. (2011) that priming increases seed vigour which fosters growth under stress condition. Untreated seeds were observed to have highest percentage germination of 55\% in the 50ppm arsenic polluted soil while $25 \%$ was recorded for the $150 \mathrm{ppm}$ arsenic polluted soil. Also, germination and percentage rate of improvement in wheat by SA has also been reported (AlHakimi and Hamada, 2001).

Similarly, an improved germination rate and percentage by ascorbate and sodium salicylic acid treatments in wheat (Al-Hakimi and Hamada, 2001). The result of this study also showed that seed treatment increased plant height, circumference and number of leaves when compared to untreated seeds of okra seeds. This also conforms to the study of Rehman et al. (2011) who stated that cucumber plant performed better when supplemented with SA. In the present study, it was recorded that germination increased at low concentrations of arsenic (50ppm). The results indicate that low concentration of arsenic could stimulate the growth of okra seedlings. According to Abedin and Meharg (2002), germination and early seedling growth was decreased in rice plant as the concentration of arsenic increases with stronger inhibition in root resulting in inhibition of plant growth and decreased biomass. This could be attributed to the fact that roots are the first part which comes in contact with toxic substance.

Applications of arsenic at various concentrations has shown that plant height, number of leaves and stem circumference of untreated seeds were significantly affected by the arsenic treatments compared to salicylic treated seeds. Similar to this is the report of Shaibur et al. (2009) who stated that plant growth was inhibited in non-primed Ipomoea aquatic plant. Typical symptoms of arsenic toxicity are inhibition of seed germination, reduction in plant height and root length, wilting and necrosis of leaf blades, decrease in shoot growth and lower fruit and grain yield as (Abedin et al., 2002).

\section{CONCLUSION}

The study showed that application ant treatment of seeds with salicylic acid improved the germination and growth of okra seeds grown on arsenic acid polluted soil compared to untreated seeds. Hence, seed priming with different concentrations can be successfully used to improve the germination and seedling growth in okra seeds as well as other economic crops in contaminated soil.

\section{REFERENCES}

Abedin MJ, Meharg AA. Relative toxicity of arsenite and arsenate on germination and early seedling growth of rice (Oryza sativa L.). Plant and Soil, 2002;243: 57-66.

Abedin MJ, Feldmann J, Meharg AA. Uptake kinetics of arsenic species in rice plants. Plant Physiol 2002;128:1120-1128.

Afzal I, Basra SMA, Ahmad N, Farooq M. Optimization of hormonal priming techniques for alleviation of salinity stress in wheat (Triticum aestivum L.). Caderno de Pesquisa Série Biologia, 2005;17:95-109.

Al-Hakimi AMA, Hamada AM. Counteraction of salinity stress on wheat plants by grain soaking in ascorbic acid, thiamin or sodium salicylate. Biol. Plant., 2001;44:253-261.

Ashraf M, Foolad MR. Presowing seed treatment-A shotgun approach to improve germination, growth and crop yield under saline and non-saline conditions. Adv. Agron. 2005;88: 223-271. 
Canakci S. Effects of salicylic acid on growth, biochemical constituents in pepper (Capsicum annuum L.) seedlings pak. J Biol Sci. 2011;14:300-4.

Carvalho RF, Piotto FA, Schmid D, Peters LP, Monteiro, CC, Azevedo RA. Seed priming with hormones does not alleviate induced oxidative stress in maize seedlings subjected to salt stress. Sci Agri. 2011;68: 598-602.

Gholamali A, Seyed AMMS, Saeed Y. Effect of auxin and salt stress $(\mathrm{NaCl})$ on seed germination of wheat cultivars (Triticum aestivum L). Pakistan Journal of Biological Sciences 2007;10(15):2557-2561.

Hussein JH. Effect of Seed Priming treatment with Salicylic Acid on Viability of Okra (Abelmoschus esculentus L.) Seeds. Euphrates Journal of Agriculture Science 2017;7(2): 1-9.

Liu X, Zhang S, Shan X, Zhu YG. Toxicity of arsenate and arsenite on germination seedling growth and amylolytic activity of wheat. Chemosphere 2005;61:293-301.

Mei L, Wan X, Huang Z, Chen T, Li X, Liu Y. First evidence on different transportation models of arsenic and phosphorus in arsenic hyperaccumulator Pteris vittata. Environ. Poll. 2012;161:1-7.

Rehman H, Farooq M, Basra SMA, Afzal I. Hormonal priming with salicylic acid improves the emergence and early seedling growth in cucumber. J. Agric. Soc. Sci. 2011;7:109-113.

Shaibur MR, Islam T, Kawai S. Response of leafy vegetable Kalmi (Water Spinach; Ipomoea aquatica L.) at elevated concentrations of arsenic in hydroponic culture. Water Air Soil Pollut. 2009;202:289-300.

Taiz L, Zeiger E. Plant Physiology ( $4^{\text {th }}$ Ed.). Sunderland, Massachusetts: Sinauer Associates, Inc. 2006:103-12 